JST 8 (2) 2019
JURNAL SENI TARI
Terakreditasi SINTA 5
http://iournal.unnes.ac.id/siu/index.php/ist

\title{
Nilai Mistis pada Bentuk Pertunjukan Kesenian Kuda Lumping Satrio Wibowo di Desa Sanggrahan Kabupaten Temanggung
}

\author{
Amanda Laras Sakanthi ${ }^{1}$, Wahyu Lestari ${ }^{2}$ \\ Jurusan Pendidikan Sendratasik, Fakultas Bahasa dan Seni Universitas Negeri Semarang
}

\begin{tabular}{|c|c|}
\hline Info Artikel & Abstrak \\
\hline & Bentuk pertunjukan kesenian Kuda Lumping Satrio Wibowo Temanggung dibagi menjadi tiga \\
\hline Sejarah Artikel & ping, pertunjukan tari Bali, dan pertunjukan $L e c$ \\
\hline Diterima : & lah untuk menemukan dan menganalisis nilai mist \\
\hline 30 Septe & $\begin{array}{l}\text { anggrahan Kabupaten Temanggung } \\
\text { a Lumping Satrio Wibowo di Desa }\end{array}$ \\
\hline Disetujui & Sanggrahan Kabupaten Temanggung. Metode yang digunakan dalam penelitian adalah metode \\
\hline 10 Novemver 2019 & kualitatif dengan pendekatan etnokoreologi. Teknik pengumpulan data meliputi teknik observasi, \\
\hline Dipublikasikan : & wawancara, dokumentasi. Teknik keabsahan data menggunaka \\
\hline 27 Nove & $\begin{array}{l}\text { menunjukan pertunjukan Kuda Lumping Satrio Wibowo Temanggung mengandung nilai mistis } \\
\text { yaitu pada bagian semedi, kesurupan, dan terdapat sesaji pada saat pertunjukan, gerak saat } \\
\text { melakukan atraksi, tata rias busana Leak dan Barongan Bali, properti yang berwujud jaran yang } \\
\text { dipercaya memiliki penunggu di dalamnya, penari Kuda Lumping saat kesurupan bergerak di luar }\end{array}$ \\
\hline $\begin{array}{l}\text { Keywords: } \\
\text { The form of the show, Art, } \\
\text { Mystical Value }\end{array}$ & $\begin{array}{l}\text { batas manusia biasa. Saran bagi pemerintah yakni memberikan penghargaan dan pengakuan } \\
\text { kepada kesenian Kuda Lumping Paguyuban Satrio Wibowo Temanggung, sehingga semangat } \\
\text { berlatih agar dapat berkreasi, berkembang, memberikan hiburan kepada masyarakat dan } \\
\text { melestarikan kesenian Kuda Lumping Satrio Wibowo Temanggung. }\end{array}$ \\
\hline
\end{tabular}

\begin{abstract}
The form of Kuda Lumping Satrio Wibowo Temanggung is divided into three namely Kuda Lumping dance performances, Balinese dance performances, Leak and Barongan Bali performances. The purpose of this study was to find and analyze the mystical values found in the Kuda Lumping Satrio Wibowo Society in Sanggrahan Village, Temanggung Regency and describe the form of performances in the Kuda Lumping Satrio Wibowo in Sanggrahan Village, Temanggung District. The method used in this research is a qualitative method with ethnochoreological approach. Data collection techniques include observation techniques, interviews, documentation. . The data validity technique used the triangulation technique. The results showed that the Kuda Lumping Satrio Wibowo Temanggung show contained mystical values, namely in the semedi, possession, and there were offerings at the time of the show, movements when performing attractions, costume and make-up of Leak and Barongan, the properties (Jaran) is believed to have a watchman therein, the dancers motions when possessed is beyond normal human limits. Advice to the goverment can give appreciation and recognition to Kuda Lumping Satrio Wibowo Temanggung, so that the spirit of practice in order to be creative, develop, and provide entertainment to the community and preserve the Kuda Lumping art of Satrio Wibowo Temanggung.
\end{abstract}

(C) 2019 Universitas Negeri Semarang

\footnotetext{
$\triangle$ Alamat korespondensi:

Gedung B2 Lantai 1 FBS Unnes

Kampus Sekaran, Gunungpati, Semarang, 50229

Email : 1.laras.sakanthi@gmail.com
} ISSN 2503-2585 


\section{PENDAHULUAN}

Nilai mistis merupakan keyakinan yang hidup dalam alam pikiran kolektif masyarakat. Alam pikiran kolektif akan abadi, meskipun masyarakat telah berganti generasi (kecuali kalau masyarakat tersebut lenyap). Keyakinan ini telah hidup bersamaan dengan lahirnya masyarakat Jawa, diturunkan dari generasi ke generasi hingga kini. Sebuah pertunjukan tidak terlepas dari sesaji yang dipercaya untuk menghormati arwah leluhur yang hadir pada acara pertunjukan. Kesenian Kuda Lumping Satrio Wibowo Temanggung memiliki nilai mistis yang dapat dilihat dari bentuk pertunjukannya. Bentuk pertunjukan pada kesenian Kuda Lumping Satrio Wibowo dibagi menjadi tiga bagian yaitu, penari Kuda Lumping, penari Bali, penari Leak dan Barongan Bali. Nilai mistis kesenian Kuda Lumping Satrio Wibowo Temanggung yaitu terdapat Bentuk pertunjukan Kuda Lumping Satrio Wibowo memiliki nilai mistis dalam pertunjukannya yaitu nilai kepercayaan kepada Tuhan Yang Maha Esa dan nilai kepercayaan kepada roh leluhur saat melakukan semedi pada malam Sura di sungai Mandhang. Nilai menghormati kepada roh disekitar pertunjukan dan nilai kebersamaan saat menyediakan sajen. Nilai keberanian pada diri penari Kuda Lumping yang ingin melakukan pertunjukan atraksi atau intrance.

Penelitian sejenis yaitu penelitian yang dilakukan oleh Mukhlas Alkaf, dimuat dalam jurnal ilmiah Insitut Seni Indonesia Surakarta tahun 2017 yang berjudul "Spiritualitas Mistis di Balik Ekspresi Kesenian Rakyat Jaranan". Dalam penelitian yang dilakukan oleh Mukhlas, mengkaji tentang kepercayaan masyarakat setempat yang menganut agama Islam, tetapi tidak meninggalkan kepercayaan yang ditinggalkan oleh nenek moyang mereka. Adat istiadat para leluhurnya masih dipelihara, demikian pula adat istiadat yang mengatur keseimbangan harmoni antara manusia dan alam. Terdapat garis relasi yang tampak kuat yang mengungkap bahwa adat istiadat yang mereka praktekan dalam kehidupan sehari-hari memiliki kaitan erat dengan sistem kepercayaan yang mereka anut salah satunya dalam keterlibatan penampilan kesenian rakyat yaitu kesenian jaranan. Penampilan kesenian tidak hanya memiliki fungsi hiburan dan rekreasi saja, tetapi juga untuk sistem religi seperti ruwatan desa atau hajatan. Aspek religius dalam kesenian ini yaitu adanya kesurupan pada kesenian jaranan yang melibatkan sesaji, ritual, dan mantra, merupakan indikasi bahwa sebuah pementasan kesenian jaranan pada saat khusu seperti ritual adat, tidak hanya sebuah ekspresi semata, tetapi memiliki keterkaitan cita-cita masyarakat pendukungnya. Persamaan penelitian yang dilakukan oleh Mukhlas Alkaf dengan penelitian ini yaitu tentang kepercayaan kepada agama islam, tetapi tidak meninggalkan kepercayaan adat istiadat yang ditingalkan nenek moyang yang berkaitan dengan mistis. Perbedaan dengan penelitian Mukhlas Alkaf kajian yang diteliti. Mukhlas Alkaf hanya meneliti spiritualitas mistis sedangkan peneliti meneliti nilai mistis.

Penelitian yang dijadikan bahan referensi selanjutnya adalah penelitian yang dilakukan oleh Abrilia Dwi Alfaningrum tahun 2016 dimuat dari skripsi Seni Tari dengan judul "Bentuk Pertunjukan Kesenian Barongan Wahyu Budaya di Dukuh Karang Rejo Desa Loram Kulon Kecamatan Jati Kabupaten Kudus". Dalam penelitian yang dilakukan oleh Abrilia mengkaji tentang bentuk pertunjukan dari kesenian Barongan Wahyu Budaya di Dukuh Karang Rejo Desa Loram Kulon Kecamatan Jati Kabupaten Kudus. Bentuk pertunjukan kesenian Barongan ini memiliki tiga tahap penyajian yaitu tahap pra tontonan, dimulai dari iringan yang mulai ditabuh sebagai pertanda pertunjukan akan segera dimulai. Tahap kedua yaitu pmentasan. Dimulai dari adegan sesembahan kemudian dilanjutkan pada pertunjukan inti yaitu adegan barongan. Dilanjutkan dengan adegan jaran kepang dan penutup. Tahap ketiga yaitu arak-arakan. Dilaksanakan setelah acara inti selesai sekitar pukul 13.00 WIB dan dimulai dari tempat awal pertunjukan rute selanjutnya adalah mengelilingi desa dengan tujuan akhir di rumah Bapak RT/RW. Persamaan dengan peneliti ini adalah 
sama-sama mengkaji bentuk pertunjukan. Perbedaannya yaitu terletak pada objek kajiannya.

Masalah pada penelitian ini adalah bagaimana bentuk pertunjukan pada kesenian Kuda Lumping paguyuban Satrio Wibowo Temanggung dan apa nilai mistis yang terdapat pada kesenian paguyuban Kuda Lumping Satrio Wibowo Temanggung. Tujuan dari penelitian ini adalah untuk mendeskripsikan bentuk pertunjukan pada kesenian Kuda Lumping Satrio Wibowo dan mencari, menemukan, dan menganalisis nilai mistis yang terdapat pada kesenian Kuda Lumping Satrio Wibowo Temanggung.

Nilai adalah sesuatu yang berharga, bermutu, menunjukkan kualitas, dan berguna bagi manusia. (Notonegoro dalam Kaelan 2000). Menurut asal katanya, kata mistik berasal dari bahasa Yunani mystikos yang artinya misteri atau rahasia (Shadily 1983:263). Dari teori Notonegoro dalam Kaelan dan Shadily maka dapat disimpulkan bahwa nilai mistik adalah nilai yang berhubungan dengan manusia, untuk memenuhi kebutuhan hidup jasmani atau ragawi, sehingga dapat mengadakan suatu kegiatan tanpa meninggalkan nilai moral manusia itu sendiri.

Bentuk adalah wujud yang dapat dilihat, dengan wujud dimaksudkan kenyataan konkrit didepan kita sedangkan wujud abstrak hanya dapat dibayangkan (Bastomi 1990: 55). Soedarsono (1999: 4) mengutarakan bahwa sebuah pertunjukan merupakan perpaduan antara berbagai aspek penting yang menunjang seperti lakon, pemain, busana, iringan, tempat pentas dan penonton. Kusmayati (2000: 75) mengutarakan bahwa pertunjukan adalah aspek-aspek yang di visualisasikan dan diperdengarkan mampu mendasari suatu perwujudan yang disebut sebagai seni pertunjukan. Penelitian ini peneliti menggunakan perpaduan teori yang dikemukakan oleh Soedarsono dan Maryono Berdasarkan teori yang dikemukakan oleh Soedarsono dan Maryono dapat disimpulkan bahwa suatu pertunjukan terjadi karena adanya beberapa elemen pertunjukan. Elemenelemen pertunjukan tari meliputi tema, lakon, pemain (pelaku), gerak, iringan, tata rias dan busana, properti, tempat pentas, tata cahaya dan penonton.

\section{METODE PENELITIAN}

Secara umum metode penelitian diartikan sebagai cara ilmiah untuk mendapatkan data dengan tujuan dan kegunaan tertentu. Kegiatan penelitian dilakukan secara ilmiah, cara ilmiah berarti cara-cara tersebut didasarkan pada ciri-ciri keilmuan, yaitu rasional, empiris, dan sistematis (Sugiyono 2010:2). Penelitian yang dilakukan oleh peneliti termasuk jenis peneliti seni. Penelitian seni mempersyaratkan memiliki kepekaan atau penghayatan yang cukup tinggi terhadap seni, khususnya di bidang yang diminati dan ditekuni peneliti. Peneliti seni harus bisa merasakan denyut dan getar seni yang dikajinya, peneliti sen tidak sekedar mengamati dengan cara melihat dan mendengar saja (Rohidi 2011:47).

Pendekatan penelitian atau pandangan yaitu cara melihat, bagaimana peneliti memandang sesuatu. Pendekatan yang digunakan dalam penelitian ini adalah pendekatan etnokoreologi untuk mengkaji bentuk pertunjukan. Pendekatan etnokoreologi dimana merupakan disiplin ilmu yang membahas penelitian tentang tari dan merupakan solusi bagi penelitian tari-tarian Indonesia yang masuk kategori tari rakyat non barat. Pendekatan etnokoreologi banyak menerapkan teoriteori dari berbagai disiplin yang disebut pendekatan multidisipliner (Pramutomo 2007:104).

Etnokoreologi dapat didefinisikan sebagai kerangka pemikiran dengan asumsi-asumsi, model, konsep-konsep, metode penelitian, metode analisis serta hasil analisis yang tertentu, yang digunakan untuk memahami, menjelaskan dan menafsirkan tarian-tarian sebagai gejala kebudayaan di kawasan Nusantara. Paradigma atau perspektif yang digunakan bisa bervariasi tergantung pada tahap kegiatan yang dilalui. Tahap-tahap tersebut adalah: (a) tahap pengumpulan data (penelitian), (b) tahap penulisan etnografi, (c) tahap analisis atau penyusunan teori (Pramutomo 2007:105). Pada tahap pengumpulan data, perspektif yang digunakan adalah perspektif emik 
(emic) yakni sudut pandang pelaku atau masyarakat atau orang yang diteliti dilakukan untuk menghindari etnosentrisme dalam memahami tari-tarian yang diteliti. Pada tahap berikutnya yakni tahap penulisan etnografi, maka perspektif yang digunakan adalah perspektif emiketnik yang mempertahankan istilah-istilah lokal dalam etnografi, sedangkan penjelasannya diberikan oleh peneliti dengan menggunakan bahasa yang berlaku dalam dunia para peneliti. Selanjutnya tahap analisis atau penyusunan teori, peneliti biasanya perlu mengambil perspektif yang lebih komparatif, karena hanya dengan perspektif komperatif ini keistimewaan, kekhasan atau makna dari tari-tarian yang diteliti akan dapat lebih ditonjolkan.

Peneliti melakukan pendekatan pada bentuk pertunjukan Kesenian Kuda Lumping Satrio Wibowo Temanggung dengan memfokuskan pada bagian bentuk pertunjukan melalui elemen-elemen bentuk seperti gerak, iringan, tata rias dan busana, tempat pertunjukan dan segala pendukung pertunjukan. Dari pengamatan tersebut dapat dideskripsikan tentang bentuk pertunjukan Kesenian Kuda Lumping Satrio Wibowo Temanggung.

Lokasi penelitian dilakukan di Paguyuban Satrio Wibowo di Desa Sanggrahan Kabupaten Temanggung. Teknik pengumpulan data dilakukan dengan menggunakan teknik observasi, wawancara, dan dokumentasi. Teknik observasi yang dilakukan peneliti untuk mengumpulkan data adalah observasi partisipasi pasif yaitu peneliti datang dan mengamati orang yang sedang melakukan kegiatan tetapi tidak ikut aktif dalam kegiatan. Dalam penelitian ini peneliti observasi pada saat proses latihan dan juga pada saat pementasan Kuda Lumping Satrio Wibowo Temanggung.

Teknik wawancara dalam penelitian ini menggunakan wawancara terstruktur, artinya peneliti dalam melakukan wawancara dengan informan didasarkan pada jenis-jenis pertanyaan yang telah dirancang dan dibuat peneliti. Informan yang dipilih adalah informan yang dianggap menguasai tentang Kuda Lumping Satrio Wibowo dan dipercaya menjadi sumber data yang jelas. Peneliti mewawancarai Bapak Jumadi selaku ketua Paguyuban Satrio Wibowo mengenai latar belakang Kuda Lumping Satrio Wibowo, ide pembuatan garap gerak Kuda Lumping Satrio Wibowo, dan juga proses latihan. Wawancara Bapak Mukadi selaku tetua setempat guna mendapatkan informasi mengenai tujuan dibentuknya paguyuban Satrio Wibowo Temanggung, dan faktor penunjang dan penghambat pertunjukan. Selanjutnya peneliti juga mewawancarai pihak-pihak yang menjadi anggota paguyuban Kuda Lumping Satrio Wibowo terutama yang pernah mengalami hal mistis seperti kesurupan dan juga selaku penari dalam pertunjukan Kuda Lumping Satrio Wibowo yaitu Mas Abdul selaku penari utama, Mba Ulfa selaku penari putri Bali, dan Mas Maman selaku penari Leak yang sering mengalami kesurupan. Peneliti mewawancarai mengenai kejadian apa yang dirasakan sebelum dan sesudah mengalami kesurupan, dan bagaimana bisa mengalami hal seperti kesurupan dan berapa lama waktu yang dibutuhkan penari untuk menguasai tari pada pertunjukan Kuda Lumping Satrio Wibowo.

Selanjutnya wawancara dengan pemusik yaitu Mas Rizal dan Mas Dian mengenai alat musik yang digunakan untuk mengiringi pertunjukan Kuda Lumping Satrio Wibowo, jumlah pemusik yang mengiringi pertunjukan Kuda Lumping Satrio Wibowo, urutan iringan musik, kesulitan dan hambatan yang dirasakan sebagai pemusik dalam pertunjukan pertunjukan Kuda Lumping Satrio Wibowo.

Teknik pengumpulan data melalui dokumentasi dilakukan pada saat awal observasi, wawancara, dan juga pementasan. Dokumentasi dilakukan pada saat latihan dan pada saat pertunjukan berlangsung untuk mendapatkan data-data yang diperlukan. Peneliti wawancara serta mengambil gambar atau foto yang berkaitan nilai mistis dan bentuk pertunjukan Kuda Lumping Satrio Wibowo. Dokumentasi dilakukan pada saat proses latihan halaman rumah bapak Jumadi, dan juga pada saat pertunjukan Kuda Lumping 
Satrio Wibowo berupa gambar foto penari dan pemusik Kuda Lumping Satrio Wibowo, foto-foto tata rias dan tata busana dan juga alat musik, tempat pertunjukan, penonton, serta peneliti meminta dokumentasi berupa video kepada Bapak Jumadi.

Teknik keabsahan data menggunakan triangulasi. Teknik triangulasi merupakan teknik untuk verifikasi data melalu berbagai cara pandang sehingga dapat ditemukan kesimpulan yang mantap. Teknik triangulasi yang digunakan dalam penelitian ini yaitu teknik triangulasi sumber, triangulasi teknik, dan triangulasi waktu.

Teknik analisis data pada penelitian ini dilakukan dengan cara menganalisis data menggunakan konsepkonsep yang telah disusun sebelumnya pada rumusan masalah. Rumusan masalah pada penelitian ini yaitu bagaimana bentuk pertunjukan kesenian Kuda Lumping Satrio Wibowo dan bagaimana nilai mistis yang terdapat pada kesenian paguyuban Kuda Lumping satrio wibowo. Langkah-langkah analisis data dilakukan secara sistematis dan serempak, melalui proses pengumpulan data, mereduksi, mengklasifikasi, mendeskripsikan, dan menyaji semua informasi secara efektif telah terkumpul. Proses pengumpulan data dan menyeleksi data yang diperoleh, selanjutnya menyederhanakan data dengan cara mengurangi atau membuang yang tidak perlu kemudian mengkelompokannya secara terpisah sesuai bentuk dan jenisnya.

Reduksi data memberikan gambaran yang lebih jelas pada data yang didapat. Pada penelitian nilai mistis pada bentuk pertunjukan Kuda Lumping Satrio Wibowo di Desa Sanggrahan Kabupaten Temanggung, peneliti terlebih dahulu mengumpulkan dan merangkum keseluruhan data yang didapat melalui observasi, wawancara, dan dokumentasi yang berupa foto dan video. Penyajian data dapat dilakukan dengan bentuk uraian singkat, bagan, hubungan antara kategori dan sejenisnya. Setelah peneliti mengumpulkan data dan merangkum keseluruhan data yang didapat melalui observasi, wawancara, dan dokumentasi. Kemudian data hasil penelitian disajikan dengan bentuk uraian mulai dari ide serta bentuk pertunjukan Kuda Lumping Satrio Wibowo Temanggung. Penarikan kesimpulan merupakan temuan baru yang sebelumnya belum pernah ada, temuan tersebut berupa deskripsi atau gambaran suatu objek yang wujudnya masih hipotesis. Setelah peneliti melakukan reduksi data dan penyajian data barulah peneliti melakukan tahap akhir yaitu penarikan kesimpulan terkait dengan rumusan masalah yang diajukan.

Teknik analisis data menggunakan triangulasi yaitu mereduksi dan meyajikan data serta menarik keseimpulan secara selektif yang terkumpul (Miles dan Huberman, Terj Rohidi 2011:239).

\section{HASIL DAN PEMBAHASAN}

Pertunjukan Kuda Lumping

Satrio Wibowo Temanggung memiliki nilai mistis, yang dapat dilihat dari bentuk pertunjukan Kuda Lumping Satrio Wibowo. Paguyuban Kuda Lumping Satrio Wibowo Temanggung dalam melakukan pementasannya didukung oleh wayang atau penari Kuda Lumping pria dan penari Bali perempuan. Menurut Jumadi (wawancara dengan Jumadi, 24 Desember 2018) hal ini dimaksudkan sebagai penambah daya tarik bagi penonton. Umumnya, penonton pria lebih menyukai tarian yang dilakukan oleh penari wanita. Sebaliknya, penonton wanita lebih menyukai tarian yang dilakukan oleh penari laki-laki. Atas dasar pemikiran tersebut, maka dalam kelompok paguyuban yang dipimpinnya sengaja dilakukan pencampuran pemain, pada saat penelitian berlangsung terdapat perwakilan penari baik laki-laki ataupun perempuan.

Secara keseluruhan teknik pertunjukan Kuda Lumping Satrio Wibowo terbagi menjadi tiga bagian, yaitu bagian pertama tari Kuda Lumping, bagian kedua tari bali, dan bagian terakhir Leak dan barongan. Ketiga bagian itu adalah Tari Kuda Lumping, penari yang berjumlah 15 penari laki-laki dengan format 4 orang di depan kemudian bagian belakang mengikuti dan menyisakan satu ruang kosong. Karena satu penari berada 
di depan sebagai pemimpin atau wiroyudha.

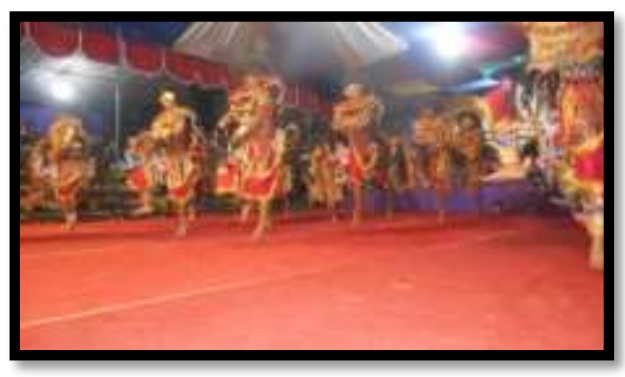

Foto 1. Pemain Kuda Lumping Satrio Wibowo Temanggung

(Dokumentasi Amanda, 19 Oktober 2018)

Tari Bali, pada Tari Bali dibagi lagi menjadi 3 tarian, yaitu tari Cendrawasih dibawakan oleh 1 orang penari putri, tari Pendhet dibawakan oleh 2 orang penari putri, dan terakhir Gambyongan dibawakan oleh 3 orang penari putri. Pada bagian ini biasanya penari putri berkolaborasi dengan wiroyudha, seperti sedang digoda atau dalam bahasa Jawa diledhek.

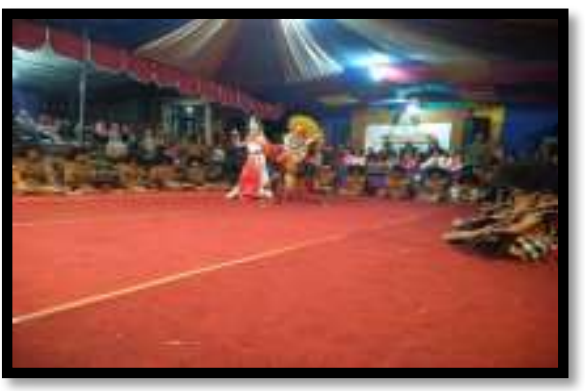

Foto 2. Penari Bali Tari Cendrawasih Satrio Wibowo Temanggung

(Dokumentasi Amanda, 19 Oktober 2018)

Bagian ketiga, Leak dan Barongan. Leak yang ditampilkan biasanya yang berwarna putih, dan hitam. Masingmasing Leak diperankan oleh 1 orang penari. Tidak boleh dipakai oleh sembarang orang. Kemudian untuk Barongan, diperankan oleh 2 orang penari dan tidak boleh diperankan oleh sembarang orang. Hanya diperankan oleh Jumadi dan Nadim.



Foto 3. Tari Leak Hitam Bali Satrio Wibowo Temanggung

(Dokumentasi Amanda, 19 Oktober 2018)

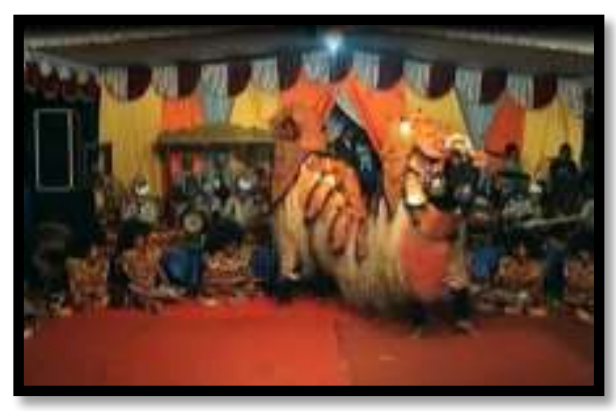

Foto 4. Barongan Bali Satrio Wibowo Temanggung

(Dokumentasi Amanda, 19 Oktober 2018)

Pertunjukan Kuda Lumping Satrio Wibowo pada umumnya dipentaskan pada malam hari, sekitar pukul 20.00 sampai selesai. Kuda Lumping Satrio Wibowo ini biasanya ditarikan untuk puncak dalam suatu acara. Sebelum proses pertunjukan dimulai, ketua paguyuban terlebih dahulu berdoa pada "leluhur" yang "sengaja diundang" dengan membakar kemenyan di pelataran yang menjadi lokasi pementasan yang bertujuan agar pertunjukan Kuda Lumping Satrio Wibowo dapat berjalan dengan lancar, kemudian membakar kemenyan yang diletakan pada Leak dan Barongan. Menurut Jumadi (wawancara: 24-122018) roh leluhur yang sengaja diundang berasal dari Sungai Mandhang yang berasal dari Desa Temandhang Kecamatan Sanggrahan. Biasanya, mengundang roh leluhur itu dilaksanakan setian bulan Sura dengan mengambil air dari Sungai Mandhang. Jumadi menambahkan, ada juga roh yang tidak berasal dari Sungai Mandhang yang memasuki penari dari paguyuban Satrio Wibowo. Permintaan sajen dari roh 
tersebut juga beragam, ada yang minta memakan bunga, beling, atau minta makanan dari penjual makanan yang ada di sekitar lokasi pertunjukan.

Nilai mistis dalam bentuk pertunjukannya yaitu nilai kepercayaan kepada Tuhan Yang Maha Esa dan nilai kepercayaan kepada roh leluhur saat melakukan semedi pada malam Sura di sungai Mandhang. Nilai menghormati kepada roh disekitar pertunjukan dan nilai kebersamaan saat menyediakan sajen. Nilai keberanian pada diri penari Kuda Lumping yang ingin melakukan pertunjukan atraksi atau intrance.

Nilai keyakinan pada roh yang ada didalam Leak Barongan Bali. Nilai estetis magis karena adanya properti dapat menambah kegagahan penari Kuda Lumping. Nilai kepercayaan kepada Tuhan bahwa Tuhan menciptakan makhluk yang tidak terlihat. Nilai kepercayaan karena tidak semua percaya adanya makhluk halus. Nilai ungkapan syukur karena pertunjukan berjalan dengan lancar. Nilai menghormati dan kebersamaan. Pagi sebelum dimulai pertunjukan dilakukan selamatan dan doa bersama semua grup Kuda Lumping Satrio Wibowo Temanggung, supaya diberi kelancaran dilengkapi sesaji yag sudah disediakan diantaranya yaitu ingkung (ayam yang dibumbu kuning dicampur dengan kelapa), bubur merah putih yang wajib ada, jadah pasar, kendi kecil berisi air, sisir, kaca, bedak, kembang telon, kelapa muda, rokok, dan menyan. Adanya sesaji juga terdapat nilai menghormati pada roh yang terdapat disekitar tempat pertunjukan. Ketika diadakan slametan juga terdapat nilai kebersamaan, karena pada saat slametan semua anggota Paguyuban Satrio Wibowo Temanggung makan secara bersamaan, dalam tampah dan dengan piring daun pisang sehingga timbul rasa akrab disbanding makan dengan piring sendiri-sendiri.

Pertunjukan yang mengandung nilai mistis terdapat pada cerita atau lakon dalam adegan Leak dan Barongan. Cerita yang diangkat yaitu legenda atau kisah Leak yang mengganggu ketentraman warga Desa sehingga membuat marah prajurit berkuda yang siap melawan Leak. Nilai yang terkandung didalamnya yaitu nilai kepercayaan kepada sebuah cerita legenda, karena cerita diatas hanya sebuah legenda yang belum tentu kebenaran.

Nilai menghargai juga terdapat pada busana Barongan dan Leak karena dalam Barongan terdapat roh penunggu yang harus didoakan jika sudah melakukan pertunjukan, karena setiap pertunjukan diibaratkan semua hal buruk dari yang diruwat akan masuk kedalam Barongan. Nilai yang terkandung di dalamnya yaitu nilai keyakinan pada roh penunggu yang ada didalam Barongan dan Leak juga sesekali ingin di doakan.

\section{SIMPULAN}

$\begin{array}{ccc} & \text { Bentuk pertunjukan } & \text { kesenian } \\ \text { Kuda Lumping } & \text { Satrio } & \text { Wibowo }\end{array}$ Temanggung dibagi menjadi tiga yaitu pertunjukan Kuda Lumping, pertunjukan tari Bali, dan pertunjukan Leak dan Barongan Bali. Pertunjukan Kuda Lumping Satrio Wibowo Temanggung mengandung nilai mistis yaitu pada bagian semedi, intrance atau kesurupan, dan terdapat sesaji pada saat pertunjukan, gerak saat melakukan atraksi, tata rias busana Leak dan Barongan Bali, properti yang berwujud jaran yang dipercaya memiliki penunggu didalamnya, penari Kuda Lumping saat kesurupan bergerak diluar batas manusia biasa, dan penonton dapat merasakan mistis atau ikut mengalami kesurupan. Bentuk pertunjukan Kuda Lumping Satrio Wibowo memiliki nilai mistis dalam pertunjukannya yaitu nilai kepercayaan kepada Tuhan Yang Maha Esa dan nilai kepercayaan kepada roh leluhur saat melakukan semedi pada malam Sura di sungai Mandhang. Nilai menghormati kepada roh disekitar pertunjukan dan nilai kebersamaan saat menyediakan sajen. Nilai keberanian pada diri penari Kuda Lumping yang ingin melakukan pertunjukan atraksi atau intrance.

Nilai keyakinan pada roh yang ada dalam Leak Barongan Bali. Nilai estetis magis karena adanya properti dapat 
menambah kegagahan penari Kuda Lumping. Nilai kepercayaan kepada Tuhan bahwa Tuhan menciptakan makhluk yang tidak terlihat. Nilai kepercayaan karena tidak semua percaya adanya makhluk halus. Nilai ungkapan syukur karena pertunjukan berjalan dengan lancar.

$$
\text { Saran dari peneliti dapat }
$$

memberikan penghargaan dan pengakuan kepada kesenian Kuda Lumping Paguyuban Satrio Wibowo Temanggung, sehingga semangat berlatih agar dapat berkreasi, berkembang, memberikan hiburan kepada masyarakat dan melestarikan kesenian Kuda Lumping Satrio Wibowo Temanggung.

\section{DAFTAR PUSTAKA}

Alfaningrum, Abrilia Dwi. 2016.Bentuk Pertunjukan Kesenian Barongan Wahyu Budaya di Dukuh Karang Rejo Desa Loram Kulon Kecamatan Jati Kabupaten Kudus Pati. Skripsi. Universitas Negeri Semarang.

Alkaf, Mukhlas. Spiritualitas Mistis di Balik Ekspresi Kesenian Rakyat Jaranan. Jurnal. Institut Seni Indonesia, Yogyakarta.

Bastomi, Suwaji. 1988. Apresiasi Kesenian Tradisional. Semarang: IKIP Semarang Press.

Hadi, Y. Sumandiyo. (2011). Koreorafi (Bentuk-Teknik-Isi). Yogyakarta: Cipta Media.

Maryono. (2015). Analisis Tari. Surakarta: ISI Press.

Pramutomo, RM. (2007). Etnokoreologi Nusantara (batasan kajian, sistematika, dan aplikasi keilmuannya). Surakarta: ISI Press.

Rohidi, Tjeptjep Rohendi. (2011). Meteologi Penelitian Seni. Semarang: Cipta Prima Nusantara.

Soedarsono. (2000). Seni Pertunjukan Indonesia Di Era Globalisasi. Yogyakarta: Gajah Mada University Press.

Sugiyono. (2009). Metode Penelitian Kuantitatif Kualitatif dan $R \& D$. Bandung: Alfabeta $\mathrm{Cv}$. 